\title{
Descrição morfológica para identificação das plântulas de nove espécies lenhosas de uma floresta de restinga*
}

\author{
Maria Claudjane Jerônimo Leite Alves ${ }^{1,2}$, Patrícia Barbosa Lima ${ }^{\text {, }}$ \\ Liliane Ferreira Lima ${ }^{1} \&$ Carmen Silvia Zickel ${ }^{1}$
}

${ }^{1}$ Departamento de Biologia - Botânica, Universidade Federal Rural de Pernambuco - UFRPE, Av. Dom Manuel de Medeiros, s/n, Dois Irmãos, CEP 52117-900, Recife, PE, Brasil

${ }^{2}$ Autor para correspondência: Maria Claudjane Jerônimo Leite Alves, e-mail: mariaclaudjane@hotmail.com

*Parte do mestrado do primeiro autor, Programa de Pós-graduação em Botânica da Universidade Federal Rural de Pernambuco, Recife, PE, Brasil.

\begin{abstract}
ALVES, M.C.J.L., LIMA, P.B., LIMA, L.F. \& ZICKEL, C.S. Morphological description to identify the seedlings of woody species. Biota Neotrop. 13(3): http://www.biotaneotropica.org.br/v13n3/en/abstract?identificationkey+bn03413032013
\end{abstract}

\begin{abstract}
The seedling stage is an important stage of the cycle plant because it provides relevant information that can be used in taxonomic and ecological studies. Studies that focus on morphological description reveal characters who often tend to disappear during the development of the plant, but that may be relevant to the differentiation of taxa. Furthermore, through the characterization of the different types of seedlings present in different ecosystems is possible to infer the evolutionary history of plant groups, serving also as subsidy for regeneration studies. Based on these, this study aims to characterize the morphology of seedlings of nine woody species with cotyledons CHR, with a view to identifying the species, providing information for taxonomic, phylogenetic and ecological, besides setting up a dichotomous key. The study area was a forest restinga located on the southern coast of Pernambuco, seeds were collected from mature fruits and sown in trays containing sandy soil, and kept in a greenhouse where his development was monitored daily. As a result, we found that some species, such as Andira fraxinifolia, Casearia javitensis, Eugenia hirta, Maytenus obtusifolia, Protium heptaphyllum and Ximenia american at seedling stage showed different characteristics of young plant as quantity of leaflets, texture and shape of eophylls. These data were similar to those found in other studies for tropical forests. From the results it can be concluded that the different morphological features between the seedling analyzed are important for use in the identification and recognition of the same field, as well as the characterization of its species.
\end{abstract}

Keywords: native species, cotyledons, eophylls, Atlantic forest.

ALVES, M.C.J.L., LIMA, P.B., LIMA, L.F. \& ZICKEL, C.S. Descrição morfológica para identificação das plântulas de nove espécies lenhosas de uma floresta de restinga. Biota Neotrop. 13(3): http://www. biotaneotropica.org.br/v13n3/pt/abstract?identification-key+bn03413032013

Resumo: O estágio de plântula é uma importante fase do ciclo vegetal, pois fornece informações relevantes que podem ser utilizadas em estudos taxonômicos e ecológicos. Estudos que enfocam a descrição morfológica revelam caracteres que, muitas vezes tendem a desaparecer ao longo do desenvolvimento do vegetal, mas que podem ser relevantes para a diferenciação dos táxons. Além disso, através da caracterização dos distintos tipos de plântulas presentes nos diferentes ecossistemas é possível inferir sobre a historia evolutiva dos grupos vegetais, servindo também como subsídio para estudos de regeneração. Frente ao exposto, o presente estudo objetiva caracterizar a morfologia das plântulas de nove espécies lenhosas, com cotilédones CHR, com vistas à identificação das espécies, fornecendo subsídios para trabalhos taxonômicos, filogenéticos e ecológicos, além de montar uma chave de identificação para estas espécies. A área de estudo foi uma floresta de restinga localizada no litoral sul de Pernambuco, sementes foram obtidas de frutos maduros e semeadas em bandejas contendo substrato arenoso, sendo mantidas em casa de vegetação onde seu desenvolvimento foi acompanhado diariamente. Como resultado, foi possível verificar que algumas espécies, tais como Andira fraxinifolia, Casearia javitensis, Eugenia hirta, Maytenus obtusifolia, Protium heptaphyllum e Ximenia americana, na fase de plântula apresentaram características morfológicas diferentes da fase adulta como a quantidade de folíolos, textura e forma dos eofilos. Estes dados foram similares aos encontrados em outros estudos para florestas tropicais. A partir dos resultados, pode-se concluir que os diferentes caracteres morfológicos entre as plântulas estudadas são importantes para serem utilizados na identificação e reconhecimento das mesmas em campo, bem como na caracterização de suas espécies.

Palavras-chave: espécies nativas, cotilédones, eofilos, floresta Atlântica. 


\section{Introdução}

O reconhecimento morfológico das espécies em suas fases iniciais de vida agrega valores importantes para a taxonomia de diversos grupos vegetais, pois amplia a quantidade de informações morfológicas que podem ser utilizadas em conjunto com os caracteres tradicionalmente empregados para a identificação das espécies, proporcionando maiores chances para a correta identificação, sobretudo das espécies vegetais florestais (Gurgel et al. 2012). No entanto, ainda observa-se uma enorme lacuna de estudos sobre a caracterização morfológica de plântulas para vários grupos e uma escassez de espécimes no estágio de plântula nos herbários (Garwood 2009), restringindo, consequentemente, o conhecimento referente à taxonomia e biologia das espécies vegetais.

Levando-se em consideração a grande quantidade de táxons existentes nas florestas tropicais, torna-se evidente a ocorrência de problemas taxonômicos em muitos grupos vegetais, que possivelmente poderiam ser solucionados a partir do incremento de estudos com enfoque na morfologia externa de plântulas (Oliveira 2001, Battilani et al. 2006). Dessa forma, análises descritivas de plântulas e/ou indivíduos jovens são essenciais para auxiliar na elucidação de questões relativas à taxonomia e à filogenia (Duke 1965, Ng 1973, 1978, Silva 2001), uma vez que podem fornecer importantes informações para a caracterização de famílias, gêneros e até mesmo de espécies (Oliveira 1993, Rodrigues et al. 2012). Sendo assim, através da descrição morfológica de plântulas é possível designar estados de caráter ancestrais ou derivados, que podem desaparecer na planta adulta, e que são considerados importantes no estabelecimento de conexões filogenéticas entre os grupos que apresentem tais características (Ressel et al. 2004).

Primariamente, pode-se destacar a relevância do tipo de germinação para a diferenciação das espécies, que associada ao formato da lamina foliar, do tipo de margem, ápice, posição dos eofilos, presença ou ausência de látex ou indumento, dentre outras características, podem dar mais robustez à sistemática de vários táxons (Gurgel et al. 2012). Um ponto importante sobre os estudos de plântulas é que ao entender como os distintos tipos de plântulas se distribuem dentro dos táxons e como esses se distribuem no ambiente, é possível inferir tanto a respeito da história evolutiva desses grupos (Oliveira 2001), quanto na caracterização das estratégias de sobrevivência das comunidades vegetais. Isso pode ser explicado pelo fato de que muitas vezes as características abióticas do habitat (luz, temperatura, salinidade, pluviosidade) podem interferir no aspecto geral da vegetação, influenciando, até mesmo, no estabelecimento e desenvolvimento de diversas espécies vegetais e, consequentemente, nas características das plântulas de um ecossistema (Henriques et al. 1986, Klein et al. 2007).

Para Garwood (1996) os padrões de germinação e o comportamento inicial das plântulas são úteis na percepção das estratégias de regeneração e estabelecimento em florestas tropicais úmidas. Nesses ambientes constata-se a predominância de plântulas com cotilédones dos tipos fanero-epígeo-foliáceo (PEF) e cripto-hipógeo-armazenador (CHR) (Ressel et al. 2004). As plântulas PEF geralmente são englobadas no grupo das espécies pioneiras, apresentando como principal característica um rápido crescimento, possibilitando aos seus indivíduos vantagens na competição por luz (Ressel et al. 2004). Por outro lado, plântulas CHR são frequentemente encontradas em espécies secundárias e/ou clímax, e em ambientes de floresta tropicais este tipo de plântula é abundante e extremamente importante, pois seus indivíduos formam os bancos de plântulas podendo sobreviver por um longo tempo no sub-bosque (Schiavini et al. 2001), visto que seus cotilédones possuem substâncias nutritivas armazenadas e relativamente protegidas (i.e., em geral o tegumento da semente funciona como uma barreira protetora) (Ressel et al. 2004).

Em face dos argumentos supracitados, este estudo teve como principal objetivo descrever a morfologia das plântulas de nove espécies lenhosas representativas de uma área de restinga pernambucana (Almeida Junior et al. 2009). Haja vista que a identificação das plantas, a partir da fase de plântula, é difícil uma vez que os caracteres morfológicos externos de uma planta nos estádios iniciais de desenvolvimento podem ser diferentes daqueles observados no indivíduo adulto ou em plantas de espécies e gêneros afins (Amorim et al. 2006). Assim, a elucidação de suas características iniciais a partir da descrição das plântulas e da confecção de uma chave dicotômica, bem como, da ilustração dos diferentes estádios com fotografias podem servir de subsídios para a correta identificação das mesmas em campo, como também para estudos taxonômicos e ecológicos.

\section{Material e Métodos}

O estudo foi desenvolvido em uma área de 76,2 ha de vegetação de restinga localizada na Reserva Particular do Patrimônio Natural (RPPN) Nossa Senhora do Outeiro de Maracaípe (08 31' $48^{\prime \prime} \mathrm{S}$ e $35^{\circ} 01$ '05” W), litoral Sul de Pernambuco, Brasil.

O clima da área é do tipo As' (Köppen 1948), sendo os meses mais chuvosos, geralmente, maio, junho e julho, e os meses mais secos outubro, novembro e dezembro - INMET (Instituto... 2005). Com base em um estudo prévio sobre a morfofunção de plântulas (M.C.J.L. Alves, dados não publicados), realizado na fisionomia florestal da restinga de Maracaípe, foram selecionadas nove espécies lenhosas que apresentaram cotilédones do tipo cripto-hipógeoarmazenador (CHR) (ver Tabela 1). Estas nove espécies vegetais são bem representadas (Almeida Junior et al. 2009) na RPPN de Maracaípe, e foram selecionadas por serem de difícil identificação na fase de plântula.

Das espécies selecionadas, foram obtidas 100 sementes oriundas de frutos maduros coletados manualmente e de maneira aleatória de, no mínimo, três indivíduos de cada uma das espécies, sendo todas as sementes beneficiadas, ou seja despolpadas, e levadas para germinar em bandejas contendo solo arenoso, proveniente da restinga estudada.

Foram consideradas germinadas as sementes que elevaram o epicótilo acima do nível do solo (Brown 1992). A fase de plântula foi considerada aquela em que os eofilos estiveram totalmente formados (Feliciano 1989).

As características morfológicas descritas foram às mesmas sugeridas por Roderjan (1983) e Oliveira (1993), para tanto foram

Tabela 1. Famílias e espécies lenhosas com cotilédones CHR da restinga da RPPN de Maracaípe, Pernambuco, Brasil. Classificação em ordem alfabética por família e espécie seguindo APG III (Angiosperm... 2009).

Table 1. Families and woody species with cotyledons CHR in restinga RPPN Maracaípe, Pernambuco, Brazil. Rating alphabetically by family and species following APG III (Angiosperm... 2009).

\begin{tabular}{ll}
\hline \multicolumn{1}{c}{ Família } & \multicolumn{1}{c}{ Espécie } \\
\hline Anonaceae & Annona pickelii (Diels) H.Rainer \\
Burseraceae & Protium heptaphyllum (Aubl.) Marchand \\
Celastraceae & Maytenus obtusifolia Mart. \\
Fabaceae & Andira fraxinifolia Benth. \\
Lauraceae & Ocotea notata (Nees) Mez \\
Lecythidaceae & Eschweilera ovata (Cambess.) Miers \\
Myrtaceae & Eugenia hirta O. Berg \\
Olacaceae & Ximenia americana L. \\
Salicaceae & Casearia javitensis Kunth \\
\hline
\end{tabular}


selecionados cinco indivíduos. As terminologias empregadas para a morfologia geral das plântulas, tais como o tipo de indumento, forma dos eofilos, tipo de ápice e de base, se basearam em Radford et al. (1974). Durante um ano, diariamente as características morfológicas das plântulas foram observadas, anotadas e registradas a partir de fotografias (com câmera fotográfica digital Cannon modelo A - 410).

As espécies foram classificadas de acordo com o APG III (Angiosperm... 2009) e para a confecção da chave de identificação dicotômica, foram utilizados caracteres dos eofilos juntamente com a filotaxia e morfologia geral do limbo foliar e do metafilo.

\section{Resultados}

Importantes características morfológicas foram observadas durante a fase de plântula de algumas das espécies analisadas, tais como, Andira fraxinifolia, Protium heptaphyllum, Maytenus obtusifolia, Eugenia hirta, Casearia javitensis e Ximenia americana, quando comparadas aos indivíduos adultos das mesmas.

As plântulas de Andira fraxinifolia apresentaram eofilos com 3 a 5 folíolos, diferindo da fase adulta, onde apresenta 9 a 11 folíolos. A textura foliar também foi variável, onde nas folhas totalmente expandidas a textura era membranácea enquanto plântulas e cartácea nos indivíduos adultos. Nesta espécie, pode-se observar algumas variações na morfologia foliar dos folíolos durante o desenvolvimento dos indivíduos, nos quais os dois folíolos basais apresentavam-se ovados e os três folíolos terminais elípticos.

Em Protium heptaphyllum, além da mudança na quantidade dos folíolos entre o estágio de plântula e os indivíduos adultos, houve uma variação no tipo de margem foliar, tendo sido observado nas plântulas eofilos com 3 folíolos e com margem serreada, diferindo dos indivíduos adultos que possuem folhas com 5 a 7 folíolos e margem inteira.

Já em Maytenus obtusifolia a mudança ocorreu apenas no tipo margem foliar, observando-se eofilos com margem serreada nas plântulas e margem inteira na fase adulta.

Em Eugenia hirta, a textura foliar também foi modificada durante o seu desenvolvimento inicial, com folhas totalmente expandidas membranáceas na plântula e folhas totalmente expandidas cartáceas nos indivíduos adultos. Já na espécie Ximenia americana foi evidenciado, inicialmente, que os eofilos apresentavam forma oblanceolada, porém, posteriormente, ao surgir o primeiro metafilo, houve uma alteração nessa característica e os eofilos adquiriram a forma obovada.

Levando em consideração a importância de identificar qual o padrão de distribuição das folhas no caule para identificação dos grupos taxonômicos, e considerando que esse padrão pode ser variável durante o desenvolvimento inicial de algumas espécies, ressalta-se os tipos de filotaxia encontrados nas espécies analisadas: (i) alterna para Andira fraxinifolia, Ocotea notata, Eschweilera ovata, Maytenus obtusifolia, Annona pickelii e Ximenia americana; (ii) oposta para Casearia javitensis, Eugenia hirta e Protium heptaphyllum. Com exceção das espécies $C$. javitensis e $E$. hirta (que passaram de filotaxia oposta para alterna e de oposta para oposta cruzada, respectivamente), não foram observadas nas demais espécies distinção morfológica e alterações na filotaxia na fase plântula em comparação à adulta.

\section{Descrições morfológicas das plântulas de nove espécies lenhosas}

\section{Annona pickelii (Diels) H.Rainer (Annonaceae)}

A elevação do epicótilo (Figura 1A) caracterizando a germinação ocorreu entre a $33^{\mathrm{a}}$ e a $35^{\mathrm{a}}$ semanas de semeadura. Após dois dias da elevação do epicótilo, observou-se que a plântula possuía raiz axial com algumas raízes secundárias delgadas e terciárias curtas, marrom-claras, sem odor e sem nodulações. O coleto e hipocótilo não foram evidentes. Cotilédones do tipo CHR. Epicótilo curto (ca. 0,3 cm), cilíndrico, densamente piloso, verde, com três entrenós curtos. Cada entrenó apresentava dois catafilos opostos. Primeiro eofilo (Figura 1B) séssil, estipulado; simples, alterno (Figura 1C), 2,8 $\times 1,3 \mathrm{~cm}$, elíptico, ápice agudo, base atenuada, membranáceo, margem ciliada. Venação peninérvea, puberulento nas faces adaxial e abaxial, discolor, inodoro e sem exsudação.

\section{Protium heptaphyllum (Aubl.) Marchand (Burseraceae)}

A elevação do epicótilo caracterizando a germinação (Figura 1D) ocorreu entre a segunda e a quarta semanas de semeadura. Após 45 dias da elevação do epicótilo a plântula apresentava raiz axial, levemente sinuosa, branca, sem raízes secundárias, coleto pouco evidente (ca. 0,2 cm), ligeiramente intumescido, glabro, verdeclaro, hipocótilo não evidente. Cotilédones do tipo CHR. Epicótilo longo com 2,9-7,9 cm (Figura 1E), cilíndrico, piloso, verde-claro. Primeiro par de eofilos (Figura 1F) peciolados; compostos, opostos, trifoliolados, com 3,3-4,6 × 0,9-1,7 cm. O folíolo é elíptico, ápice agudo, base obtusa, cartácea, margem serreada. Venação cladódroma, faces adaxial e abaxial glabras, inodoro e sem exsudação.

\section{Maytenus obtusifolia Mart. (Celastraceae)}

A elevação do epicótilo (Figura $1 \mathrm{G}$ ) caracterizando a germinação ocorreu entre a primeira e a terceira semanas de semeadura. Após 15 dias da elevação do epicótilo a plântula apresentava raiz axial, levemente sinuosa, marrom-clara, zona pilífera bem desenvolvida, coleto evidente, ligeiramente intumescido, glabro, marrom-claro, hipocótilo não evidente, cotilédones do tipo CHR. Epicótilo de tamanho curto (Figura 1H), com 1,5-1,8 cm, cilíndrico, glabro, verdeclaro. O primeiro par de eofilos (Figura 1I) peciolados, estipulados na base; simples, opostos, 0,9-1,1 × 3,0-5,0cm, elípticos, ápice arredondado, base aguda, cartáceos, margem serrilhada. Metafilos alternos. Venação craspedódroma, face adaxial e abaxial glabras, inodoro e sem exsudação.

\section{Andira fraxinifolia Benth. (Fabaceae)}

A elevação do epicótilo (Figura 2A) caracterizando a germinação ocorreu entre a segunda e a quarta semanas após a semeadura. Após 20 dias da elevação do epicótilo a plântula apresentava raiz axial espessa, longa, sem nodulação. As poucas raízes secundárias eram delgadas, marrom-claras, coleto e hipocótilo pouco evidentes, de coloração marrom-escura, glabros. Cotilédones do tipo CHR. Epicótilo longo ca. 9,5 cm (Figura 2B), cilíndrico, glabro, marromescuro, com dois a quatro entrenós curtos (ca. $0,4 \mathrm{~cm}$ ) possuindo um catafilo alterno cada. Primeiro par de eofilo (Figura 2C) peciolados, estipulados, compostos, alternos, imparipinados, 6,7-9,2 ×3,0-3,2 cm, com 3 a 5 folíolos, ovados ( 2 folíolos basais) e estreitamente elípticos (3 folíolos terminais), avermelhados no início do desenvolvimento. Ápice do eofilo caudado, base arredondada nos 2 folíolos basais e oblíqua nos 3 folíolos terminais, membranáceos, margem inteira. Venação craspedódroma, glabro em ambas as faces, inodoro e sem exsudação. O primeiro metafilo (Figura 2C) apresentou os mesmos caracteres do eofilo.

\section{Ocotea notata (Nees) Mez (Lauraceae)}

A elevação do epicótilo (Figura 2D) caracterizando a germinação ocorreu entre a $11^{\mathrm{a}}$ e a $12^{\mathrm{a}}$ semanas de semeadura. Após nove dias da elevação do epicótilo a plântula apresentava raiz axial delgada, levemente sinuosa, marrom-clara, com poucas raízes secundárias, 

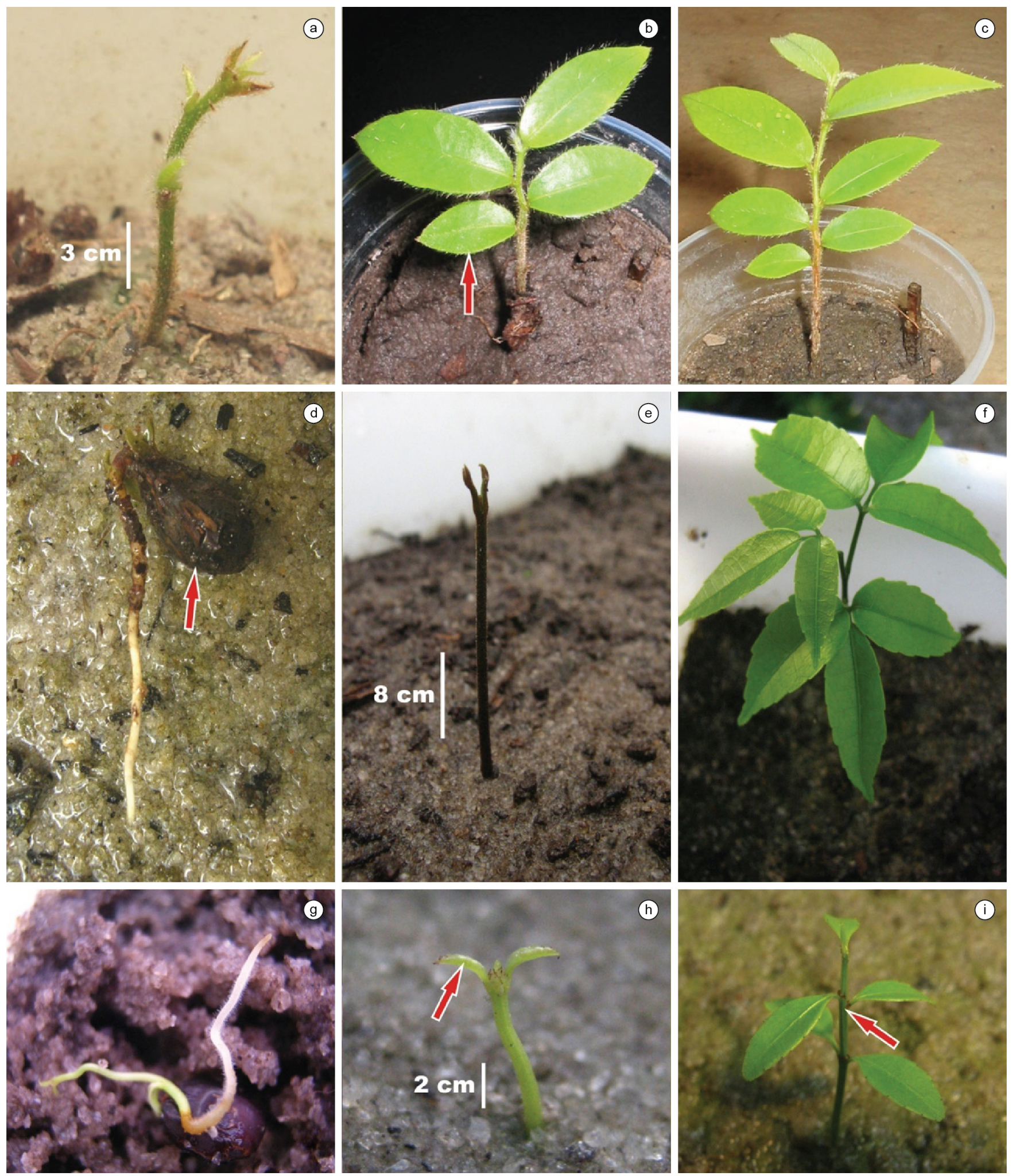

Figura 1. Aspecto geral das plântulas das espécies: Annona pickelii (Diels.) H.Rainer: a (elevação do epicótilo), b (destaque para o primeiro eofilo), c (planta jovem com filotaxia alterna); Protium heptaphyllum (Aubl.) Marchand.: d (germinação, destaque para o cotilédone cripto-hipógeo-armazenador), e (elevação do epicótilo), f (primeiro par de eofilo composto trifoliolado); Maytenus obtusifolia Mart.: g (germinação), h (epicótilo e destaque para o primeiro par de eofilo, com filotaxia oposta), i (planta jovem, destaque para metafilos com filotaxia alterna). Os destaques são apontados com seta vermelha.

Figure 1. General appearance of the seedlings of the species the species: Annona pickelii (Diels.) H.Rainer: a (elevation epicotyl), b (especially the first eophyll), c (young plant with alternate phyllotaxy); Protium heptaphyllum (Aubl.) Marchand.: d (germination, especially the cotyledon crypto-hypogeal-reserve), e (elevation epicotyl), f (first pair of eophyll compound three sheets); Maytenus obtusifolia Mart.: $\mathbf{g}$ (germination), h (epicotyl and especially the first couple of eophyll with opposite phyllotaxy), i (young plant, especially metaphylls with alternating phyllotaxy). The highlights are pointed with red arrow. 
curtas, sem odor, sem nodulações, coleto e hipocótilo não evidentes. Apresentou alça epicotilar emergindo com dois a cinco catafilos alternos pré-formados, glabros e de coloração branca. Cotilédones do tipo CHR. Epicótilo curto, medindo ca. de 2,0 cm, verde a avermelhado, delgado, cilíndrico, puberulento. Eofilo (Figura 2E) curto-peciolado, sem estípulas; simples, alterno (Figura 2F), 0,9-1,0 × 2,0-3,0 cm, estreitamente elíptico, ápice acuminado, base atenuada, membranáceo, margem inteira. Venação peninérvea, glabro em ambas as faces, discolor, inodoro, sem exsudação.

\section{Eschweilera ovata (Cambess.) Miers (Lecythidaceae)}

A elevação do epicótilo (Figura $2 \mathrm{G}$ ) caracterizando a germinação ocorreu na quarta semana após a semeadura. Aos seis dias após a elevação do epicótilo a plântula apresentava uma raiz axial longa,
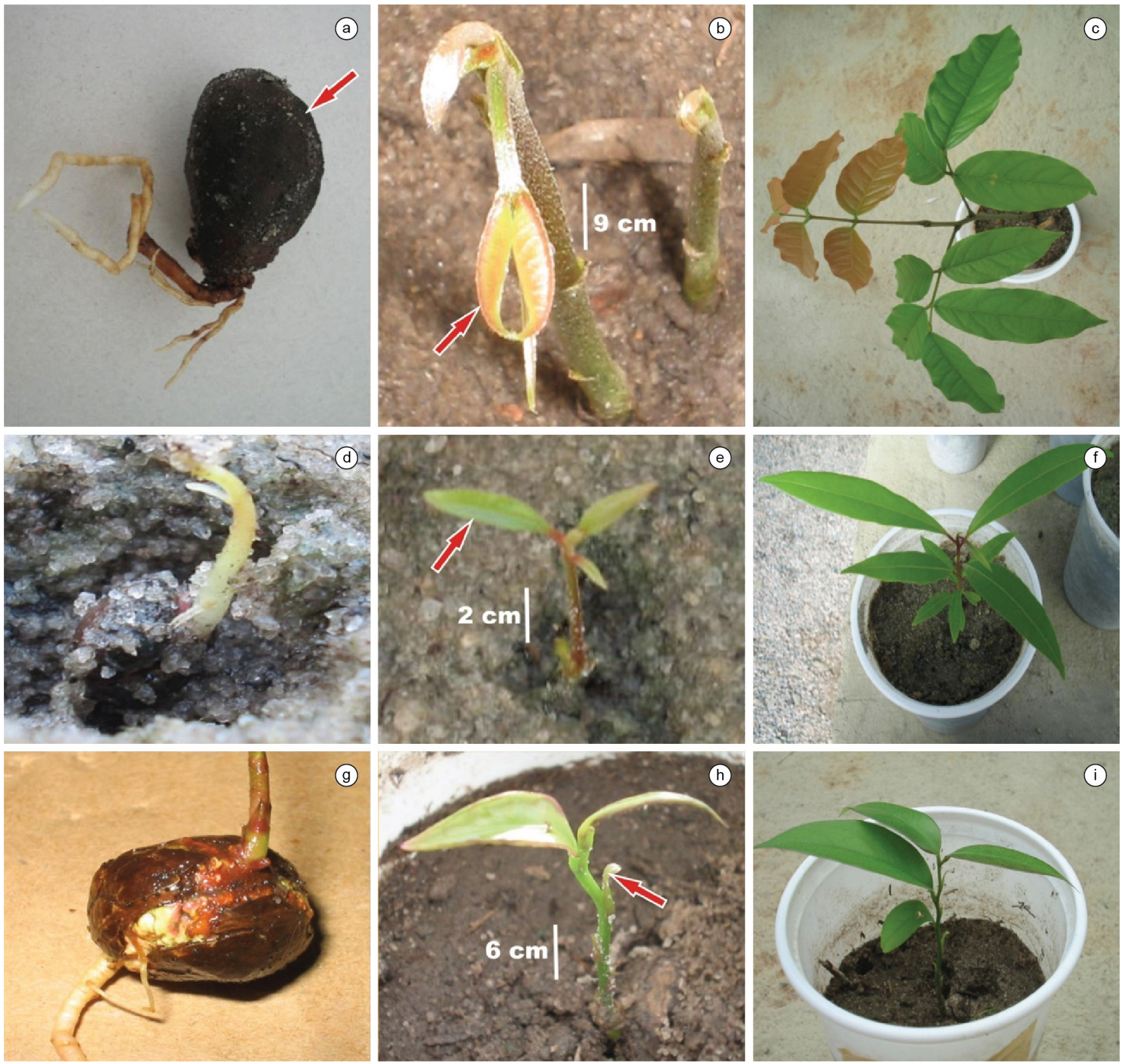

Figura 2. Aspecto geral das plântulas das espécies: Andira fraxinifolia Benth.: a (germinação e destaque para o cotilédone hipógeo criptocotiledonar armazenador), b (epicótilo e destaque para o surgimento do primeiro eofilo composto), c (planta jovem com filotaxia alterna); Ocotea notata (Nees) Mez: d (elevação do epicótilo), e (destaque para o primeiro eofilo), f (planta jovem com filotaxia alterna); Eschweilera ovata (Cambess.) Miers.: g (cotilédone criptohipógeo-armazenador), h (elevação do epicótilo e destaque para a formação de catafilos), i (planta jovem com filotaxia alterna). Os destaques são apontados com seta vermelha.

Figure 2. General appearance of the seedlings of the species the species: Andira fraxinifolia Benth.: a (germination and especially the hypogean cotyledon cryptocotyledonary storer), b (epicotyl and especially the emergence of the first eophyll compound), c (young plant with alternate phyllotaxy); Ocotea notata (Nees) Mez: d (elevation epicotyl), e (especially the first eophyll), f (young plant with alternate phyllotaxy); Eschweilera ovata (Cambess.) Miers.: $\mathbf{g}$ (cotyledon crypto-hypogeal-reserve), $\mathbf{h}$ (high epicotyl and particularly for the formation of cataphylls), $\mathbf{i}$ (young plant with alternate phyllotaxy). The highlights are pointed with red arrow. 
marrom-clara, sem odor e nodulações e com muitas raízes secundárias delgadas. Coleto e hipocótilo não evidentes. Cotilédones do tipo CHR. Epicótilo longo (ca. 6,5 cm) (Figura 2H), cilíndrico, glabro, verde, com seis entrenós curtos e com um catafilo alterno cada. Eofilo (Figura 2I) curto-peciolado, sem estípulas; simples, alterno, 2,0-2,2 $\times 1,0-1,2 \mathrm{~cm}$, elíptico, ápice acuminado, base atenuada, membranáceo, margem inteira e glabra. Venação peninérvea, glabro em ambas as faces, verde-claro, inodoro e sem exsudação.

\section{Eugenia hirta O. Berg (Myrtaceae)}

A elevação do epicótilo (Figura 3A) caracterizando a germinação ocorreu entre a $17^{\mathrm{a}}$ e a25 a semanas de semeadura. Após cinco dias da elevação do epicótilo a plântula apresentava raiz axial, levemente sinuosa e de coloração marrom-clara. Coleto e hipocótilo não evidentes. Cotilédones do tipo CHR. Epicótilo mediano, aproximadamente $3,95 \mathrm{~cm}$, cilíndrico, verde-claro e com três pares de catafilos opostos. Primeiro par de eofilos (Figura 3B) sésseis, sem estípulas, simples, opostos, 1,2-1,4 × 1,0-1,1 cm, obovados, ápice obtuso, base subcordada, membranáceos, margem inteira e ciliada. Venação cladódroma, face adaxial pilosa e abaxial glabra, inodoro, sem exsudação. No segundo nó, aos 27 dias de germinação, houve a formação do primeiro metafilo com características semelhantes ao primeiro par de eofilos passando a filotaxia a ser oposta cruzada (Figura 3C).

\section{Ximenia americana L. (Olacaceae)}

A elevação do epicótilo (Figura 3D) caracterizando a germinação ocorreu entre a primeira e a segunda semanas após a semeadura. Após 12 dias da elevação do epicótilo a plântula apresentava raiz axial, pouco sinuosa, de coloração branca. As poucas raízes secundárias eram espessas, curtas, com pêlos evidentes, sem odor, sem nodulações. O coleto era pouco evidente, levemente intumescido, glabro e branco. Hipocótilo curto (ca. $0,1 \mathrm{~cm}$ ), glabro, branco. A alça epicotilar emergiu com 7 a 9 catafilos alternos pré-formados. Cotilédones do tipo CHR. Epicótilo (Figura 3E) longo (ca. 6,7 cm), entrenó curto (ca. 0,2 cm), puberulento e verde. Primeiro eofilo (Figura 3F) séssil, sem estípulas; simples, alterno, $0,9 \times 0,2 \mathrm{~cm}$, oblanceolado, ápice mucronado, base atenuada, membranáceo e margem inteira. Venação peninérvea, glabro em ambas as faces, verde-claro, inodoro, sem exsudação. Primeiro metafilo membranáceo, curto-peciolado, 2,5-2,6 × 1,6 cm, simples, obovado, ápice oblíquo, peninérveo, faces adaxial brilhante e abaxial opaca, e demais caracteres semelhantes ao primeiro eofilo (Figura 3F).

\section{Casearia javitensis Kunth (Salicaceae)}

A elevação do epicótilo caracterizando a germinação ocorreu aproximadamente na $13^{\text {a }}$ semana após a semeadura. Após cinco dias da elevação do epicótilo a plântula apresentava raiz axial levemente intumescida (Figura 3G), sinuosa, branca a marrom-clara, com poucas raízes secundárias, curtas, sem odor, sem nodulações, coleto evidente, branco, glabro. Hipocótilo pouco evidente (ca. 0,1 cm), delgado, branco a verde-claro, cotilédones do tipo CHR. Epicótilo curto (ca. 3,0 cm), puberulento, verde-claro. Primeiro par de eofilos (Figura $3 \mathrm{H}$ ) curto-peciolados, com duas pequenas estípulas, simples, opostos, 2,8-3,0 × 8,-1,0 cm, ovados, ápice acuminado, base atenuada, membranáceos, margem inteira, peninérveos, glabros em ambas as faces, inodoros, sem exsudação. No segundo nó, aos dez dias da germinação, houve a formação do primeiro metafilo (Figura $3 \mathrm{H}$ ) com características semelhantes as doprimeiro par de eofilos, diferindo apenas na filotaxia, que passou a ser alterna, como pode ser visto na planta jovem (Figura 3I).

\section{Discussão}

A caracterização morfológica de plântulas tem sido bastante utilizada como uma ferramenta útil na sistemática de diversos grupos vegetais (Garwood 1995), pois estudos que abordam os aspectos taxonômicos dessa fase de vida da planta tendem a revelar a presença de estruturas importantes para identificação dos táxons, os quais nem sempre permanecem evidentes nos indivíduos adultos (Amorim et al. 2006). Tais estruturas transitórias permitem ampliar o conhecimento das estruturas essenciais da plântula ao longo do seu desenvolvimento e possibilitam a caracterização da espécie, especialmente aquelas de ecossistemas florestais (Gurgel et al. 2012).

Dentre as variações estruturais ocorrentes na fase pós-seminal a heterofilia é um fator comum em espécies florestais durante a fase de plântula, onde as primeiras folhas podem apresentar morfologia distinta das folhas adultas (Duke \& Polhill 1981, Montoro 2008). Esta mudança na morfologia foliar pode ser observada de acordo com Duke (1969), em espécies das famílias Anacardiaceae, Bignoniaceae, Caesalpinaceae, Fabaceae, Meliaceae, Mimosaceae e Sapindaceae. De fato, as plântulas de diferentes grupos taxonômicos, especialmente aquelas de espécies ocorrentes em florestas tropicais, podem exibir uma grande diversidade morfológica, com variações na altura, arranjo e forma das folhas, além da variação dos cotilédones dentro e entre táxons (Garwood 1995, 1996, Lopes et al. 2012).

A variação na forma das folhas juvenis apesar de ser comum a muitas espécies, nem sempre ocorre de forma gradual (Andreata 1980). A sequência de diferenciação foliar pode ser abrupta, como em muitas espécies da família Mimosaceae, ou lenta e gradual, como em muitas espécies lenhosas das famílias Fabaceae, Meliaceae e Sapindaceae (Paoli \& Santos 1998). Isto corrobora os resultados encontrados, neste estudo, para Andira fraxinifolia (Fabaceae) que apresentou mudança lenta e gradual no seu desenvolvimento foliar.

Em alguns estudos, como o de Lima et al. (2008), também foi possível verificar a diferenciação foliar na fase de plântula. Segundo esses autores, a espécie Abarema filamentosa (Benth.) Pittier apresenta um par de eofilos opostos no estágio de plântula, com mudança posterior da filotaxia para alterna. Alguns estudos mencionam a variação morfológica existente para as plântulas do grupo das Fabaceae (Oliveira 2001, Gates 1951), sendo, portanto, imprescindível aumentar o esforço no direcionamento de estudos com plântulas e plantas jovens para fins taxonômicos para esta família (Braz et al. 2009). Por ser bastante representativa na flora de diversos ecossistemas, inclusive em áreas de restinga (Gurgel et al. 2012), a caracterização morfológica das plântulas de espécies arbóreas de Fabaceae tem sido utilizada como uma ferramenta confiável para o reconhecimento das espécies em campo (Gurgel et al. 2012, Braz et al. 2009, Rodrigues \& Tozzi 2007).

Dentre as variações morfológicas observadas durante o desenvolvimento das espécies analisadas, a transição da textura foliar entre as plântulas e indivíduos adulto foi evidenciada nas espécies Eugenia hirta e Andira fraxinifolia, com folhas variando de membranáceas (plântula) a cartáceas (indivíduo adulto). Pesquisas evidenciam que algumas características morfológicas ou morfoanatômicas podem também ter relação com as características abióticas do meio em que estão inseridas. Segundo Boeger \& Wisniewski (2003) plantas que se desenvolvem em solos arenosos, como em ambientes de restinga, por exemplo, possuem folhas mais espessas como estratégia de sobrevivência nessas áreas, auxiliando na redução da perda de água, resistência ao período de maior incidência luminosa e herbivoria. Nesse contexto, os indivíduos que apresentam cotilédones do tipo CHR podem investir lentamente na formação de eofilos mais complexos e eficientes para o aproveitamento da luz difusa de ambientes sombreados (Cavichiolo 2006). O que explica a 
variação de tamanho e de formas das folhas das espécies estudadas, que cresceram e se estabeleceram em áreas sombreadas da restinga.

Porém, cabe ressaltar também, que essa mudança na textura foliar pode representar apenas uma característica transitória ao longo do ciclo de vida da planta. De acordo com Andreata \& Pereira (1990), essa mudança na textura das folhas juvenis é um fenômeno comum, pois as folhas tendem a se tornar gradualmente mais espessas, passando de membranácea à cartácea ou ainda à coriácea ao longo do desenvolvimento da planta.

\section{Conclusão}

A análise dos caracteres morfológicos das plântulas das nove espécies estudadas constatou a existência de variação nas características foliares (tais como: forma dos eofilos, consistência e filotaxia) tanto entre as espécies analisadas quanto no próprio indivíduo (em relação ao indivíduo adulto), permitindo, desta forma, sua identificação a nível específico na comunidade vegetal. Ressalta-se ainda a importância da realização de outros estudos
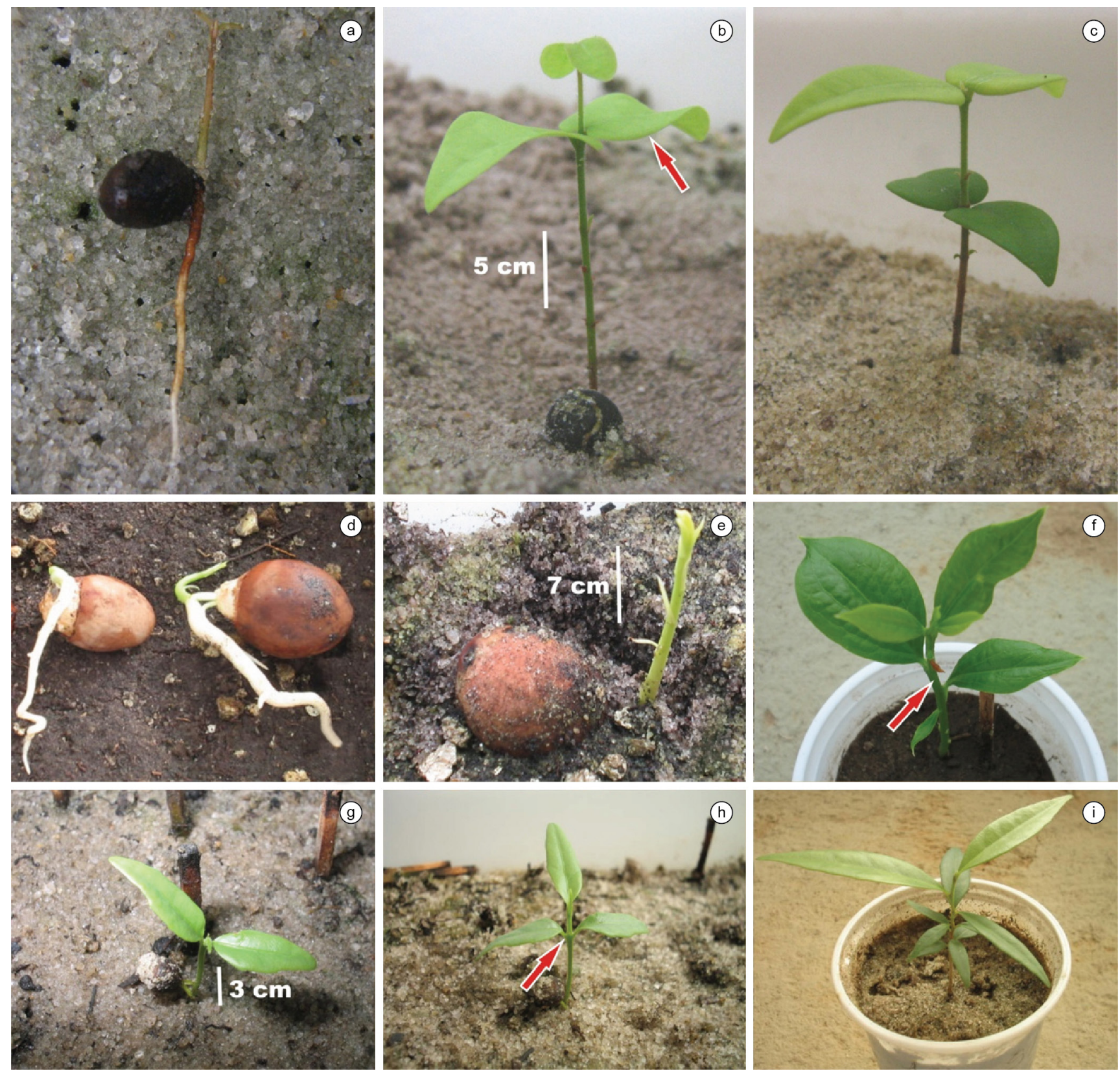

Figura 3. Aspecto geral das plântulas das espécies: Eugenia hirta O. Berg.: a (germinação e cotilédone cripto-hipógeo-armazenador), b (destaque para eofilos opostos), c (filotaxia oposta-cruzada); Ximenia americana L.: d (germinação e cotilédone cripto-hipógeo-armazenador), e (elevação do epicótilo), f (planta jovem com destaque para filotaxia alterna); Casearia javitensis Kunth.: g (elevação do epicótilo), h (destaque para os eofilos opostos) e i (planta jovem com eofilos opostos e metafilos alternos). Os destaques são apontados com seta vermelha.

Figure 3. General appearance of the seedlings of the species the species: Eugenia hirta O. Berg.: a (germination and cotyledon crypto-hypogeal-reserve), b (especially eophylls opposites), c (cross-opposite phyllotaxi); Ximenia americana L.: d (germination and cotyledon crypto-hypogeal-reserve), e (elevation epicotyl), f (especially young plant phyllotaxi switches); Casearia javitensis Kunth.: $\mathbf{g}$ (elevation epicotyl), h (especially eophylls opposite) and $\mathbf{i}$ (young plant with eophylls opposites and metaphylls alternating). The highlights are pointed with red arrow. 
com o mesmo enfoque para que seja possível ampliar o conjunto de dados ou mesmo descobrir caracteres taxonômicos potencialmente informativos para delimitação dos táxons, bem como, auxiliar nos trabalhos ecológicos que necessitem da correta identificação das plântulas (ver apêndice em anexo).

\section{Agradecimentos}

A Capes pelo auxílio financeiro. Ao Dr. Eduardo Almeida pela ajuda na identificação das espécies e pelas críticas na finalização deste trabalho. A Dra. Simone Lira e Msc. Edson Moura pelo valioso apoio nas coletas de material botânico.

\section{Referências Bibliográficas}

ALMEIDA JUNIOR, E.B., OLIVO, M.A., ARAUJO, E.L. \& ZICKEL, C.S. 2009. Caracterização da vegetação de restinga da RPPN de Maracaípe, PE, Brasil, com base na fisionomia, flora, nutrientes do solo e lençol freático. Acta Bot. Bras. 23(1):36-48. http://dx.doi.org/10.1590/ S0102-33062009000100005

AMORIM, I.L., FERREIRA, R.A., DAVIDE, A.C. \& FERREIRA CHAVES, M.M. 2006. Aspectos morfológicos de plântulas e mudas de Trema. Rev. Bras. Sementes. 28(1):86-91. http://dx.doi.org/10.1590/S010131222006000100012

ANDREATA, R.H.P. 1980. Smilax linnaeus (Smilacaceae):ensaio para uma revisão das espécies brasileiras. Arq. Jard. Bot. Rio J. 24:179-301.

ANDREATA, R.H.P. \& PEREIRA, T.S. 1990. Morfologia das plântulas de algumas espécies de Smilax L. Arq. Jard. Bot. Rio J. 41:7-34.

ANGIOSPERM PHYLOGENY GROUP - APG III. 2009. An update of the Angiosperm Phylogeny Group classification for the orders and families of flowering plants: APG III. Bot. J. Linnean Soc. 161:105-121. http:// dx.doi.org/10.1111/j.1095-8339.2009.00996.x

BATTILANI, J. L., SANTIAGO, E.F., \& SOUZA A, L.T. 2006. Morfologia de frutos, sementes e desenvolvimento de plântulas e plantas jovens de Maclura tinctoria (L.) D. Don. ex Steud. (Moraceae). Acta Bot. Bras. 20(3):581-589. http://dx.doi.org/10.1590/S010233062006000300008

BOEGER, M.R.T. \& WISNIEWSKI, C. 2003. Comparação da morfologia foliar de espécies arbóreas de três estádios sucessionais distintos de floresta ombrófila densa (Floresta Atlântica) no Sul do Brasil. Rev. Bras. Bot. 26(1):61-72. http://dx.doi.org/10.1590/S0100-84042003000100007

BRAZ, M.S.S., SOUZA, V.C., ANDRADE, L.A., BRUNO, R.L.A., OLIVEIRA, L.S.B. \& SILVA, J.M. 2009. Caracterização morfológica de frutos, sementes e plântulas de jacarandá-da-bahia (Dalbergia nigra (Vell.) Fr. All.ex.Benth) Leguminosae-Papilonoideae. Rev. Bras. Ciênc. Agrárias 4(1):67-71.

BROWN, D. 1992. Estimating the composition of a forest seed bank: a comparison of the seed extraction and seedling emergence methods. Can. J. Bot. 70(8):1603-1612. http://dx.doi.org/10.1139/b92-202

CAVICHIOLO, L.S. 2006. Aspectos morfológicos e ecológicos dos principais tipos morfofuncionais de plântulas ocorrentes na Ilha do Mel, PR. Dissertação de mestrado, Universidade Federal do Paraná, Curitiba.

DUKE, J.A. 1965. Keys for the identification of seedlings of some prominent woody species in eight forest types in Puerto Rico. Ann. Mis. Bot. Garden 52(3):314-350. http://dx.doi.org/10.2307/2394796

DUKE, J.A. 1969. On tropical seedlings. In Seeds, seedlings, systems and systematics. Ann. Mis. Bot. Garden 56(2):125-161. http://dx.doi. org $/ 10.2307 / 2394836$

DUKE, J.A. \& POLHILL, R.M. 1981. Seedlings of Leguminosae. In Advances in legumes systematic (R.M. Polhil \& P.H. Raven, eds.). Kew: Royal Bot. Gardens, p.941-949.

FELICIANO, A. L. P. 1989. Estudo de germinação de sementes e desenvolvimento da muda, acompanhado de descrições morfológicas de dez espécies arbóreas ocorrentes no semi-árido nordestino. Dissertação de mestrado, Universidade de Viçosa, Viçosa.
GARWOOD, N.C. 1995. Studies in Annonaceae. XX. Morphology and ecology of seedlings, fruits and seeds of selected Panamanian species. Bot. Jah. Systematik 117:1-152.

GARWOOD, N.C. 1996. Functional morphology of tropical tree seedlings. In: The ecology of tropical forest tree seedlings (M.D. Swaine Ed.). The Parthenon Publishing Group, New York, p.59-129.

GARWOOD, N.C. 2009.Seedlings of Barro Colorado Island and the Neotropics. Ithaca, Comstock Publishing Associates.

GATES, R.R. 1951. Epigeal germination in the Leguminosae. Bot. Gazette, 113:151-157. http://dx.doi.org/10.1086/335703

GURGEL, E.S.C., SANTOS, J.U.M., LUCAS, F.C.A. \& BASTOS, M.N C. 2012. Morfologia de plântulas de Leguminosae e o potencial sistemático. Rodriguésia 63(1):065-073. http://dx.doi.org/10.1590/ S2175-78602012000100006

HENRIQUES, R.P.B., ARAÚJO, D.S.D. \& HAY, J.D. 1986. Descrição e classificação dos tipos de vegetação da restinga de Carapebus, Rio de Janeiro. Rev. Bras. Bot. 9:173-189.

INSTITUTO NACIONAL DE METEOROLOGIA - INMET. 2005. www. inmet.gov.br (último acesso em: 10/01/2005).

KLEIN, A.S.; CITADINI-ZANETTE, V.; SANTOS, S. 2007. Florística e estrutura comunitária de restinga herbácea no município de Araranguá, Santa Catarina. Biotemas 20(3):15-26.

KÖPPEN, W. 1948. Climatologia: com un estudio de los climas de la tierra. Fondo de Cultura Economica, Mexico

LIMA, P.B., LIMA, L.F., MEDEIROS, D.P.W., \& ZICKEL, C.S. 2008. Caracterização Morfológica do Fruto, da Semente e da plântula e Morfofuncionalidade da Plântula de Abarema filamentosa (Benth.) Pittier - Mimosoideae. In: Biodiversidade, Potencial Econômico e Processos Eco-Fisiológicos em Ecossistemas Nordestinos (A. N. Moura, E. L. Araújo \& U. P Albuquerque, orgs.). COMUNIGRAF, Recife, v.1, p. 39-56.

LOPES, A., ROSA-OSMAN, S.M. \& PIEDADE, M.T.F. 2012. Caracterização morfológica das plântulas de cinco espécies arbóreas da floresta estacional semidecidual, Brasil. Floresta 42(1):105-114.

MONTORO, G.R. 2008. Morfologia de plântulas de espécies lenhosas do cerrado. Dissertação de mestrado, Universidade de Brasília, Brasília.

NG, F.S.P. 1973. Germination of fresh of Malaysian tress. Malaysian For. 36(2):54-65.

NG, F.S.P. 1978. Strategies of establishment in Malayan forest trees. In Tropical trees as living systems (P.B.P. Tomlinson \& M.H. Zimmermann, eds.). Cambridge University Press, London, p.129-162.

OLIVEIRA, E.C. 1993. Morfologia de plântulas. In Sementes florestais tropicais (I. B. Aguiar, F. M. C. Piña-Rodrigues \& M. B. Figliolia, coords). ABRATES, Brasília, p.175-213. PMid:8161251.

OLIVEIRA, D.M.D. 2001. Morfologia comparada de plântulas e plantas jovens de leguminosas arbóreas nativas: espécies de Phaseoleae, Sophoreae, Swartzieae e Tephrosieae. Rev. Bras. Bot. 24(1):85-97. http:// dx.doi.org/10.1590/S0100-84042001000100010

PAOLI, A.A.S. \& SANTOS, M.R.O. 1998. Caracterização morfológica de frutos, sementes e plântulas de Sapindus saponaria L. (Sapindaceae). Rev. Bras. Sementes 20(2):147-153.

RADFORD, A.E., DICKISON, W.C., MASSEY, J.R. \& BELL, C.R. 1974. Vascular plants sistematics. Harper and Row, New York, p.877.

RESSEL, K., GUILHERME, F.A.G. \& SCHIAVINI, I. 2004. Ecologia morfofuncional de plântulas de espécies arbóreas da Estação Ecológica do Panga, Uberlândia, Minas Gerais. Rev. Bras. Bot. 27(2):311-323. http://dx.doi.org/10.1590/S0100-84042004000200010

RODERJAN, C.V. 1983. Morfologia do estádio juvenil de 24 espécies arbóreas de uma floresta com araucária. Dissertação de mestrado, Universidade Federal do Paraná, Curitiba.

RODRIGUES, R.S. HIRT, A.P.M. \& FLORES, A.S. 2012. Morfologia de plântulas das espécies de Rhynchosia (Leguminosae, Papilionoideae) de Roraima, Brasil. Acta Bot. Bras. 26(3):585-592. http://dx.doi.org/10.1590/ S0102-33062012000300008 
RODRIGUES, R.S \& TOZZI, A.M.G.A. 2007. Morfologia de plântulas de cinco leguminosas genistóides arbóreas do Brasil (LeguminosaePapilionoideae). Acta Bot. Bras. 21(3):599-607. http://dx.doi. org/10.1590/S0102-33062007000300007

SCHIAVINI, I., RESENDE, J.C.F. \& AQUINO, F.G. 2001. Dinâmica de populações de espécies arbóreas em mata de galeria e mata mesófila na margem do Ribeirão do Panga, MG. In: Cerrado: Caracterização e
Recuperação de Matas de Galeria. (J.F. Ribeiro, C.E.L. Fonseca \& J.C. Sousa-Silva, Eds.). Embrapa-CPAC, Brasília, p.267-299.

SILVA, L.L. 2001. Morfologia, anatomia e desenvolvimento dos frutos, sementes e plântulas de Zanthoxylum rhoifolium Lam., Esenbeckia grandiflora Mart., Dictyoloma vandellianum Adr. Juss. e Balfourodendron riedelianum (Engler) Engler (Rutaceae). Tese de doutorado, Universidade Estadual Paulista, Rio Claro. 


\section{Apêndice}

Chave de identificação

Chave de identificação dicotômica de plântulas de nove espécies lenhosas com cotilédones cripto-hipógeo-armazenador (CHR) da restinga de Maracaípe, Pernambuco.

1. Eofilos compostos .3

2. Eofilos simples .4

3. Eofilos compostos trifoliolado Protium heptaphyllum

3'. Eofilos compostos pinado (imparipinado) Andira fraxinifolia

4. Eofilo oposto .5

4'. Eofilo alterno 6

5. Margem inteira

Casearia javitensis

5'. Margem ciliada

Eugenia hirta

6. Eofilo elíptico 7

6'. Eofilo de obovado a oblanceolado Ximenia americana

7. Peciolada .Annona pickelii

7'. Séssil ...9

8. Ausência de estípulas Maytenus obtusifolia

8'. Presença de estípulas na base dos eofilos Eschweilera ovata

9. Catafilos bem desenvolvidos (6 alternos) Ocotea notata 
